\title{
LC-MS/MS-based metabolites of Eurycoma longifolia (Tongkat Ali) in Malaysia (Perak and Pahang).
}

\begin{abstract}
A number of three LC-MS/MS hybrid systems (QTof, TripleTof and QTrap) has been used to profile small metabolites (m/z 100-1000) and to detect the targeted metabolites such as quassinoids, alkaloids, triterpene and biphenylneolignans from the aqueous extracts of Eurycoma longifolia. The metabolite profiles of small molecules showed four significant clusters in the principle component analysis for the aqueous extracts of E. longifolia, which had been collected from different geographical terrains (Perak and Pahang) and processed at different extraction temperatures $\left(35^{\circ} \mathrm{C}\right.$ and $\left.100{ }^{\circ} \mathrm{C}\right)$. A small peptide of leucine $(\mathrm{m} / \mathrm{z} 679)$ and a new hydroxyl methyl $\beta$-carboline propionic acid have been identified to differentiate $\mathrm{E}$. longifolia extracts that prepared at $35{ }^{\circ} \mathrm{C}$ and $100{ }^{\circ} \mathrm{C}$, respectively. From the targeted metabolites identification, it was found that 3,4ع-dihydroeurycomanone (quassinoids) and eurylene (squalene-type triterpene) could only be detected in the Pahang extract, whereas canthin-6-one-3N-oxide could only be detected in the Perak extract. Overall, quassinoids were present in the highest concentration, particularly eurycomanone and its derivatives compared to the other groups of metabolites. However, the concentration of canthin-6-one and $\beta$-carboline alkaloids was significantly increased when the roots of the plant samples were extracted at $100{ }^{\circ} \mathrm{C}$.
\end{abstract}

Keyword: LC-MS/MS; Eurycoma longifolia; quassinoids; alkaloids; triterpenes 